\title{
Survival of the Fittest: Evidence-based Interventions for Physical Inactivity amongst Student Populations
}

\author{
Stephanie C. Black \\ Edith Cowan University
}

\begin{abstract}
Lack of physical activity is a problem amongst student populations given their large proportion of desk-bound activity. Attrition from physical activity programs is widespread. Attrition is influenced by proximal and distal factors of health behaviour. This literature review provides an overview of the theoretical basis of the need for physical activity. Theories on health behaviour are compared, the most useful behaviour change models for deriving theory-based interventions are determined, and an overview of the most successful intervention techniques according to taxonomy-based meta-studies is provided. The literature indicates that integrated interventions that include multiple evidence-based, theory-driven intervention techniques can be effective for increasing physical activity behaviour in individuals and, consequently, improve health outcomes. Professional delivery and individual tailoring further increase the efficacy of interventions. Opportunities for future research are recommended in the areas of converging behaviour change theories, measurement devices for physical activity, and broadening the evidence base for the maintenance phase of health behaviour change.
\end{abstract}

Keywords: physical inactivity, attrition from exercise

\section{Introduction}

Throughout most of human history, high levels of physical activity have been required for survival; consequently, the human body is optimised for and thrives under conditions of high physical activity, while a sedentary lifestyle is outside the design parameters of the human body (Booth \& Laye, 2010; Devonshire-Gill \& Norton, 2013; Eaton \& Eaton, 2003). This is salient amongst university student populations which spend considerable time sitting while listening to lectures, reading, writing assignments and studying (Rouse \& Biddle, 2010).

Physical inactivity is ranked the fourth highest health risk factor in Australia for premature death and disability (Australian Institute of Health and Welfare, 2016). A range of clinical and epidemiological evidence shows an association between physical inactivity and mental and physical illnesses (Gebel et al., 2015; Stenholm et al., 2016; Voss, Nagamatsu, LiuAmbrose, \& Kramer, 2011). Yet, nearly 60\% of Australians over the age of 15 do not achieve sufficient physical activity to reduce this risk factor (Australian Institute of Health and Welfare, 2012). Moreover, half of Australia's college-aged population does not achieve sufficient physical activity to reduce this risk factor (Australian Bureau of Statistics, 2012, 2016). Projections estimate that a $10 \%$ reduction in physical inactivity would produce 2,000 fewer deaths in Australia (Cadilhac et al., 2011). Therefore, the statistical evidence for the risks associated with physical inactivity constitutes a significant incentive to increase physical activity. To increase physical activity in individuals, it is necessary to address the factors that contribute to successful initiation and maintenance of physical activity with effective theory-derived interventions. The aim of this article is, therefore, to identify evidence-based interventions which lead to increased physical activity, with particular regard to student populations. In order to do so, it is first necessary to examine the current literature in relation to the links between physical inactivity and ill-health. 


\section{Prevalence of physical inactivity}

According to a survey by the Australian Institute of Health and Welfare (2012) nearly $60 \%$ of Australians over the age of 15 do not achieve sufficient physical activity to meet Australia's Physical Activity and Sedentary Behaviour Guidelines (i.e., 150 to 300 minutes of moderate or 75 to 150 minutes of vigorous intensity physical activity, or an equivalent combination of both; Department of Health, 2014). University students are also prone to physical inactivity. Transition to university life is a challenging time for students, often leading to increased sedentary behaviour and decreased physical activity (Kwan, Cairney, Faulkner, \& Pullenyegum, 2012). Few current statistics are available regarding physical inactivity levels amongst Australian university students. However, an older study showed that $47 \%$ of female and $32 \%$ of male college students were insufficiently physically active (Leslie et al., 1999). Furthermore, only half of Australians aged 18 to 39 years (i.e., comprising the three age groups most represented amongst students; Australian Bureau of Statistics, 2016) achieve sufficient physical activity levels for health benefits (Australian Bureau of Statistics, 2012).

\section{Contribution of physical inactivity to the burden of disease in Australia}

To appreciate how physical inactivity is affecting Australia, determining the prevalence of physical inactivity alone is not sufficient; it is important to consider the burden of disease resulting from physical inactivity. A recent Australian study ranked physical inactivity the fourth highest health risk factor in Australia, contributing 5\% to the overall burden of disease and $33 \%$ to the total burden from coronary heart disease (Australian Institute of Health and Welfare, 2016). Scenario analyses to estimate the projected future burden of disease determined that a $10 \%$ reduction in physical inactivity in Australia would produce 6,000 fewer cases of disease and 2,000 fewer deaths (Cadilhac et al., 2011). These figures and observations make a compelling case for encouraging increased physical activity in students to offset the possibility of future ill health.

It is noteworthy that the situation is even worse for older populations. In a study undertaken in 2011, it was found that for females aged 45-64, physical inactivity was the second highest risk factor for healthy life years lost, exceeded only by tobacco use. For males aged 45-64, physical inactivity was the third highest risk factor (Australian Institute of Health and Welfare, 2016).

In 2016, 34\% of all students enrolled in formal study were over the age of 25 , and $8.5 \%$ were over the age of 45 (Australian Bureau of Statistics, 2016). This increased proportion of mature age students has implications for campus populations, with mature students at higher risk for healthy life years lost.

\section{Association between physical inactivity and specific health conditions}

\section{a) Mental health}

Mental health issues amongst student populations are increasing (Storrie, Ahern, \& Tuckett, 2010). Stallman (2010) observed that every fifth Western Australian university student faces mental health issues, with $67.4 \%$ experiencing subsyndromal symptoms. According to a recent survey by Headspace and the National Union of Students, around 80\% of Australian students reported mental health problems, such as feeling stressed, depressed and/or anxious; two-thirds of students noted high or very high psychological distress over the past 12 months; and over a third disclosed suicidal ideation (Headspace, 2017). A similarly high incidence of suicidal ideation was observed by an international study spanning 12 nations, which reported that $29 \%$ of students have contemplated suicide (Eskin, et al., 2016). 
Clinical and epidemiological evidence corroborates the existence of a relationship between physical inactivity and mental health conditions (for an overview see Voss et al., 2011). For example, evidence supporting the anti-depressive effect of physical activity has been mounting, with recent meta-analyses of random controlled trials finding strong evidence of a link between physical exercise and a decrease in depression (Josefsson, Lindwall, \& Archer, 2014; Schuch et al., 2016; Stubbs et al., 2016). Moreover, biochemical experiments and brain imaging trials support an anti-depressive effect of physical activity; explanatory mechanisms include neuroplasticity and neurotropic factors (Dishman et al., 2006) and augmentation of the kynurenine and serotonin metabolism (Agudelo et al., 2014). In addition, animal studies and human trials have shown improved cognitive function with increased physical activity, and the benefits of exercise for cognitive functions are observable across the whole lifespan from early childhood to old age (Voss et al., 2011), including all age-segments represented amongst students.

\section{b) Physical health}

Insufficient physical activity is also considered a risk factor for physical illness (Abu-Omar \& Rütten, 2008; Australian Institute of Health and Welfare, 2012). Several studies have shown that physical inactivity increases the risk of all-cause mortality (Gebel et al., 2015; Rhee, Kim, Park, Li, \& Ahn, 2012; Stenholm et al., 2016). Moreover, there is evidence of a relationship between increased physical inactivity and increased risk of obesity (Stenholm et al., 2016), diabetes (Conn et al., 2014; Eaton \& Eaton, 2017), cancer (Winzer, Whiteman, Reeves, \& Paratz, 2011) and heart disease (Shiroma \& Lee, 2010). The evident association of physical inactivity with ill health and increased mortality risk constitutes compelling motivation to encourage an increase in physical activity levels in individuals at any stage of life. This is salient for student populations, given that academic study comprises predominantly sedentary activities (Rouse \& Biddle, 2010).

Research has shown that sustainable increase of physical activity can be achieved when physical activity programs are paired with concomitant psychological interventions based on solid theory (Baker, Simpson, Lloyd, Bauman, \& Singh, 2011; Greaves et al., 2011). Therefore, the following section discusses the literature in relation to health behaviour change.

\section{Theories of health behaviour change}

\section{a) Proximal and distal factors}

Factors that influence health behaviour change are usually grouped into proximal and distal factors (Glass \& McAtee, 2006; Roux, 2004). Proximal factors are those which directly influence behaviours, such as attitudes and beliefs, whereas distal factors are those which exert an indirect or mediating influence, such as socioeconomic status and the external environment. For example, it has been well established that socioeconomic status can have a substantial influence on health behaviour (see literature review by Hanson \& Chen, 2007). However, it is not realistic for a health practitioner to try to change their client's socioeconomic status. Proximal factors are generally more influential than distal factors and present easier intervention targets; therefore, it is considered more practical to concentrate on proximal factors (Webb, Sniehotta, \& Michie, 2010).

\section{b) Coping and self-regulation}

When reviewing health behaviour theories to elucidate potential intervention targets, it is important to keep in mind that health behaviours are subject to goals and self-regulation. In 
this context, goals do not only comprise beneficial health behaviour goals (e.g., "I want to exercise more to improve my heart health"), but also potentially destructive goals that are aimed at short-term problem solving to cope with life stressors (e.g., "I will not exercise today but instead watch television to distract me from the problem I had at university today" adapted from Ingledew \& McDonagh, 1998). In order for a client to prioritise beneficial health behaviour goals over potentially destructive coping goals, cognitive and emotional self-regulation is required (Karoly, 2012; McKee \& Ntoumanis, 2014).

\section{c) Static sociocognitive health behaviour change models}

An extensive number of sociocognitive behaviour change models have been put forward to explain health behaviour. These include static models such as the health belief model, which focuses on beliefs as the most proximal predictor of behaviour (Rosenstock, 1966, 1974; Rosenstock, Strecher, \& Becker, 1988); the theories of reasoned action and planned behaviour, which focus on intention as the most proximal predictor of behaviour (Ajzen \& Fishbein, 1975, 1977; Ajzen, 1985, 1991) and protection motivation theory (Rogers, 1975, 1983), which focuses on how a person evaluates potential health threat coping mechanisms.

Interventions based on these models have been shown to be successful in initiating physical activity (De Vivo, Hulbert, Mills, \& Uphill, 2016) and maintaining it in the short to medium term (Fjeldsoe, Neuhaus, Winkler, \& Eakin, 2011) however, physical activity is seldom fully maintained in the long-term (Van Stralen, De Vries, Mudde, Bolman, \& Lechner, 2009).

\section{d) Stage models}

In attempting to improve upon the limitations of the static behaviour change models, a number of stage models have been put forward. An example is the transtheoretical model (Prochaska \& DiClemente, 1982; Prochaska \& Velicer, 1997), which focuses on self-efficacy and perceived outcomes as the most proximal predictors of behavioural change. Interventions based on the transtheoretical model are supported by research (see meta-studies by Mastellos, Gunn, Felix, Car, \& Majeed, 2014 and Van Stralen et al., 2009). However, Hutchison, Breckon and Johnston (2008) found in a meta-analysis that the majority of interventions based on the transtheoretical model failed to accurately represent all dimensions of the model.

\section{e) Hybrid models}

To account for the above limitations and the criticism that neither the static nor the stage models successfully bridge the intention-behaviour gap (Sniehotta, Scholz, \& Schwarzer, 2005), updated hybrid models have been conceived that synthesise the preceding models. The reasoned action approach (Ajzen \& Fishbein, 2005; Ajzen, 2010) incorporates elements from both static and stage models and attempts to bridge the intention-behaviour gap by focusing on increasing skills, decreasing environmental barriers and changing salient beliefs (Sniehotta et al., 2005).

The health action process approach (Schwarzer \& Luszczynska, 2008) integrates factors that influence implementation intention (i.e., distal factors, such as risk perception, and proximal factors, such as beliefs and outcome expectations) with components from the extended transtheoretical model, giving more room to account for relapse and recovery in the stages of change. The model also considers barriers to change, resources for change, and the phasespecific roles of self-efficacy during the pre-intentional motivational versus post-intentional volitional stages of change. 
The hybrid models are both theoretically comprehensive and successful in generating effective interventions (e.g., action planning, goal-setting, implementation intentions and support self-efficacy; Gaston \& Prapavessis, 2014; Hattar, Pal, \& Hagger, 2016; Sniehotta et al., 2005).

\section{f) Control theory}

Control theory is another behaviour change theory that has been successfully used to inform interventions. Control theory is part of the class of feedback loop models of behaviour change (Carver \& Scheier, 1982; Kanfer \& Goldstein, 1975; Kanfer, 1971). The efficacy of control theory based interventions (e.g., self-monitoring, Webb et al., 2010) is supported by several meta-studies and literature reviews (Michie \& Johnston, 2012; Williams \& French, 2011).

\section{Comparing models}

There is tentative consensus that the hybrid models and, to a lesser extent, the stage models are better supported for explaining health behaviour change than the static models (Sniehotta et al., 2005). Moreover, there is evidence in favour of control theory (Michie \& Johnston, 2012; Williams \& French, 2011). In conclusion, behaviour change models most conducive to the derivation of theory-driven interventions are those that address the client's stage of change, the intention-behaviour gap, and the client's capacity to self-monitor and selfregulate.

\section{Interventions for increasing physical activity}

\section{Taxonomies of behaviour change interventions}

Given the large number of behaviour change models and interventions derived from these, mapping interventions onto corresponding theories is not trivial. Several taxonomies of behaviour change interventions have been put forward (Abraham \& Michie, 2008; Michie et al., 2011; Sussman, Sun, \& Dent, 2006). A more recent taxonomy for behaviour change interventions targeting physical inactivity in individuals catalogues 40 intervention techniques (Michie et al., 2011).

\section{Comparing efficacy of interventions}

Michie, Abraham, Whittington, McAteer, and Gupta (2009) assessed 122 publications using the taxonomy of Abraham and Michie (2008), and observed that interventions that included self-monitoring and another self-regulatory technique were the most efficacious with an effect size nearly double that of any other intervention. Using Sussman et al.'s (2006) taxonomy, Hutchinson and Wilson (2012) assessed 29 studies and found a large effect for interventions incorporating motivational enhancement. In summary, the intervention techniques that have been reported to be the most successful in taxonomy-based meta-studies are self-monitoring, self-regulation, and motivational enhancement.

\section{Integrated interventions}

In practice, interventions are rarely used in isolation, but rather multiple evidence-based and theory-derived interventions are combined into integrated interventions. There is abundant evidence for the efficacy of integrated interventions for physical inactivity. For example, motivational interviewing includes the efficacious individual techniques of motivational and self-efficacy support, self-monitoring, goal-setting, and treatment planning (Greaves et al., 2011; O'Halloran et al., 2014; Pignataro \& James, 2015). Other examples of highly efficacious integrated interventions are counselling (Baker et al., 2011; Greaves et al., 2011), 
cognitive behaviour therapy (Brawley, Arbour-Nicitopoulos, \& Martin Ginis, 2013), brief interventions (Cunningham, Swanson, Holdsworth, \& O'Carroll, 2013) and action and coping planning (Sniehotta, Scholz, \& Schwarzer, 2006). These interventions are also well-known to be efficacious in many other therapeutic contexts, not just physical inactivity. They are likely to be already part of the portfolio of many student services professionals, requiring little adaptation and enabling the practitioner to target physical inactivity with high efficacy.

\section{Modes of intervention delivery}

\section{a) Tailored interventions}

Apart from the type of intervention used, numerous meta-analyses report that individually tailored interventions that are designed and administered by health professionals are more successful than self-help for targeting physical inactivity (Fjeldsoe et al., 2011; Greaves et al., 2011). One random controlled trial came to the opposite conclusion (Kinmonth et al., 2008); however, the researchers noted that the tailored physical activity intervention utilised may have been too complex and confusing compared to the control group, thereby confounding the effects.

\section{b) Frequency and mode of intervention}

Conclusions regarding the influence of frequency and delivery location on the efficacy of interventions are mixed. There is some support that interventions are more effective if they are conducted more frequently (Fjeldsoe et al., 2011; Greaves et al., 2011) and face-to-face (Fjeldsoe et al., 2011). However, some research found mixed evidence for an association between effectiveness and mode of intervention delivery (Greaves et al., 2011), and Davies, Spence, Vandelanotte, Caperchione and Mummery (2012) reported that internet delivery of interventions targeting physical inactivity is also effective.

\section{c) Training and skills}

One of the limitations of most interventions is that it is only effective if the professional performing the intervention possesses good emphatic listening skills and is well trained (Miller \& Rollnick, 2012). This places high requirements on the training and supervision of practitioners. To ensure a high standard of intervention delivery, treatment fidelity needs to be monitored. Instruments for measuring treatment fidelity have been developed for several interventions; one example is the Motivational Interviewing Treatment Integrity (MITI) scale (Moyers, Martin, Manuel, Hendrickson, and Miller, 2005).

\section{Discussion and recommendations}

The previous sections have reviewed the prevalence of physical inactivity in Australia, especially regarding student populations, the current and projected burden of disease attributable to physical inactivity in Australia, and the evidence for associations between physical activity and various mental and physical health conditions. This information has highlighted the importance of encouraging students to partake in sufficient physical activity. Attrition from physical activity programs can be influenced by proximal and distal factors of health behaviour; and to decrease attrition, self-regulation is required to prioritise beneficial health behaviour over destructive coping mechanisms. In comparing the major sociocognitive health behaviour change theories, including static, stage and hybrid models and control theory, the evidence suggests that behaviour change models that address the client's stage of change, the intention-behaviour gap and self-regulation are most useful for deriving theorybased interventions. Self-monitoring, self-regulation and motivational support are the most 
successful intervention techniques according to taxonomy-based meta-studies. Quality of delivery is also important, with professionally delivered, individually tailored, frequent interventions the most efficacious.

Therefore, within a university setting, it is likely that students can be encouraged to increase their levels of physical activity through the delivery of integrated interventions that include multiple effective intervention techniques. For example, through university health and counselling services, there are a number of interventions that, when delivered by well-trained professionals, can be effective in encouraging students to increase their levels of physical activity and consequently to improve health outcomes. Such interventions include motivational interviewing, cognitive behaviour therapy, action and coping planning, and so on. Similarly, clubs and societies can promote increased physical activity through a range of interventions that encourage students to set goals, self-monitor, remove barriers to the initiation and maintenance of physical activity, and remain motivated despite temporary lapses. Moreover, teaching personnel can encourage students to build social support networks which may lead to physical activity in an enjoyable social context, whereas university administrators could be advocating for improved funding and support for programs and facilities which encourage greater physical activity amongst students.

\section{Limitations and further research}

\section{Unifying behaviour change theories}

As previously shown, various behaviour change models partially overlap, and more research is needed to pare down and unify the overlapping models further (Noar \& Zimmerman, 2005; Weinstein \& Rothman, 2005). This would allow for more concise mapping of intervention techniques onto theories and better inform the development and selection of interventions.

\section{Measurements}

Another useful avenue for research is that related to the development of reliable measurement devices for physical activity. Accelerometers and pedometers are types of semi-automated trackers that enable easy logging of physical activity, thereby promoting self-monitoring (Choe et al., 2017). Self-monitoring, in turn, as previously shown, has positive impacts on physical activity. Congruent with this reasoning, a meta-study by Bravata et al. (2007) found that pedometer use increases participants' daily step counts. Moreover, Raedeke, Focht, and King (2010) observed that combining a pedometer intervention with cognitive-behavioural strategies increased physical activity levels in undergraduate students even more than pedometer use alone. Additionally, pedometers could be used to physically verify the accuracy of newly developed self-report measures for physical activity intervention studies and replace direct observation and self-reports, thereby increasing the accuracy of the measures (Australian Institute of Health and Welfare, 2012).

\section{Long-term maintenance of physical activity}

While much research has focused on pre-implementation, implementation and action, less research has focused on the maintenance stage of physical activity, with only approximately one out of three studies reporting the efficacy of interventions for long-term maintenance of physical activity (Fjeldsoe et al., 2011). More research is required that focuses on long-term maintenance. 


\section{Conclusion}

Similar to the general Australian population, it is important for the physical and mental health of university students to maintain sufficient physical activity. Students are engaged in much sedentary work and, given the known health risks of physical inactivity, it is important that universities consider the role they can play in encouraging and promoting greater levels of physical activity amongst students, thereby improving health outcomes. University health and counselling services, societies and clubs, teaching personnel and administrators all have their part to play in building a culture of greater physical activity on campus through integrated interventions that promote, support and encourage students to incorporate physical activity as a regular part of their university lives.

\section{Acknowledgement}

This article would not have occurred without Dr. Greg Dear sparking my interest in the topic and his helpful feedback on an early version of the paper. Special thanks and appreciation are due Susan Jessop for her invaluable feedback on the manuscript. 


\section{References}

Abraham, C., \& Michie, S. (2008). A taxonomy of behavior change techniques used in interventions. Health Psychology, 27(3), 379.

Abu-Omar, K., \& Rütten, A. (2008). Relation of leisure time, occupational, domestic, and commuting physical activity to health indicators in Europe. Preventive Medicine, 47(3), 319-323.

Agudelo, L. Z., Femenia, T., Orhan, F., Porsmyr-Palmertz, M., Goiny, M., Martinez-Redondo, V., ... \& Ruas, J. L. (2014). Skeletal muscle PGC-1 alpha modulates kynurenine metabolism and mediates resilience to stress-induced depression. Cell, 159(1), 33-45.

Ajzen, I. (1985). From intentions to actions: A theory of planned behavior. Berlin:Springer.

Ajzen, I. (1991). The theory of planned behavior. Organizational Behavior and Human Decision Processes, 50(2), 179-211.

Ajzen, I. (2010). Predicting and changing behavior: The reasoned action approach. New York: Psychology Press.

Ajzen, I., and Fishbein, M. (1975). Belief, Attitude, Intention, and Behavior: An Introduction to Theory and Research. Reading, MA: Addison-Wesley.

Ajzen, I., \& Fishbein, M. (1977). Attitude-behavior relations: A theoretical analysis and review of empirical research. Psychological Bulletin, 84(5), 888-918.

Ajzen, I., \& Fishbein, M. (2005). The influence of attitudes on behavior. In D. Albarracín, B. T. Johnson, \& M. P. Zanna (Eds.), The handbook of attitudes (pp. 173-221). Mahwah, NJ: Erlbaum.

Australian Bureau of Statistics (2012). Australian Health Survey: Physical Activity, 2011-12. (ABS Catalogue no. 4364.0). Canberra: Australian Bureau of Statistics.

Australian Bureau of Statistics (2016). Education and Work, Australia, May 2016. (ABS Catalogue no. 6227.0). Canberra: Australian Bureau of Statistics.

Australian Institute of Health and Welfare. (2012). Australia's Health 2012: In brief. AIHW.

Australian Institute of Health and Welfare (2016). Australian Burden of Disease Study: Impact and causes of illness and death in Australia 2011. Australian Burden of Disease Study series no. 3. BOD 4. Canberra: AIHW.

Baker, M. K., Simpson, K., Lloyd, B., Bauman, A. E., \& Singh, M. A. F. (2011). Behavioral strategies in diabetes prevention programs: A systematic review of randomized controlled trials. Diabetes Research and Clinical Practice, 91(1), 1-12.

Booth, F., \& Laye, M. (2010). The future: genes, physical activity and health. Acta Physiologica, 199(4), 549556.

Bravata, D., Smith-Spangler, C., Sundaram, V., Gienger, A., Lin, N., Lewis, R., . . Sirard, J. (2007). Using pedometers to increase physical activity and improve health: A systematic review. Journal of the American Medical Association, 298(19), 2296-2296.

Brawley, L. R., Arbour-Nicitopoulos, K. P., \& Martin Ginis, K. A. (2013). Developing physical activity interventions for adults with spinal cord injury. Part 3: A pilot feasibility study of an intervention to increase self-managed physical activity. Rehabilitation Psychology, 58(3), 316.

Cadilhac, D. A., Cumming, T. B., Sheppard, L., Pearce, D. C., Carter, R., \& Magnus, A. (2011). The economic benefits of reducing physical inactivity: an Australian example. International Journal of Behavioral Nutrition and Physical Activity, 8(1), 99.

Carter, T., Callaghan, P., Khalil, E., \& Morres, I. (2012). The effectiveness of a preferred intensity exercise programme on the mental health outcomes of young people with depression: a sequential mixed methods evaluation. BMC Public Health, 12(1), 1.

Carver, C. S., \& Scheier, M. F. (1982). Control theory: A useful conceptual framework for personality-social, clinical, and health psychology. Psychological Bulletin, 92(1), 111.

Conn, V. S., Koopman, R. J., Ruppar, T. M., Phillips, L. J., Mehr, D. R., \& Hafdahl, A. R. (2014). Insulin sensitivity following exercise interventions systematic review and meta-analysis of outcomes among healthy adults. Journal of Primary Care \& Community Health, 2150131913520328. 
Cunningham, M., Swanson, V., Holdsworth, R., \& O’Carroll, R. (2013). Late effects of a brief psychological intervention in patients with intermittent claudication in a randomized clinical trial. British Journal of Surgery, 100(6), 756-760.

Davies, C. A., Spence, J. C., Vandelanotte, C., Caperchione, C. M., Mummery, W. K. (2012). Meta-analysis of internet-delivered interventions to increase physical activity levels. International Journal of Behavioral Nutrition and Physical Activity, 9(1), 52.

Department of Health (2014). Australia's Physical Activity and Sedentary Behaviour Guidelines. Retrieved from http://www.health.gov.au/internet/main/publishing.nsf/content/health-pubhlth-strateg-phys-actguidelines on 16 July 2017

De Vivo, M., Hulbert, S., Mills, H., \& Uphill, M. (2016). Examining exercise intention and behaviour during pregnancy using the Theory of Planned Behaviour: A meta-analysis. Journal of Reproductive and Infant Psychology, 34(2), 122-138.

Devonshire-Gill, K. R., \& Norton, K. I. (2013). Proportion of adults achieving sufficient physical activity increases in South Australia, 1998-2010. Population Health Metrics, 11(1), 1.

Dishman, R. K., Berthoud, H.-R., Booth, F. W., Cotman, C. W., Edgerton, V. R., Fleshner, M. R., Gandevia, S. C., et al. (2006). Neurobiology of exercise. Obesity, 14(3), 345-356.

Eaton, S. B., \& Eaton, S. B. (2003). An evolutionary perspective on human physical activity: implications for health. Comparative Biochemistry and Physiology Part A: Molecular \& Integrative Physiology, 136(1), 153-159.

Eaton, S. B., \& Eaton, S. B. (2017). Physical inactivity, obesity, and type 2 diabetes: An evolutionary perspective. Research Quarterly for Exercise and Sport, 88(1), 1-8.

Eskin, M., Sun, J. M., Abuidhail, J., Yoshimasu, K., Kujan, O., Janghorbani, M., ... \& Hamdan, M. (2016). Suicidal behavior and psychological distress in university students: a 12-nation study. Archives of Suicide Research, 20(3), 369-388.

Choe, E., Abdullah, S., Rabbi, M., Thomaz, E., Epstein, D., Cordeiro, F., ... Kientz, J. (2017). Semi-Automated tracking: A balanced approach for self-Monitoring applications. IEEE Pervasive Computing, 16(1), 7484. doi:10.1109/MPRV.2017.18

Fjeldsoe, B., Neuhaus, M., Winkler, E., \& Eakin, E. (2011). Systematic review of maintenance of behavior change following physical activity and dietary interventions. Health Psychology, 30(1), 99.

Forster, M., Veerman, J., Barendregt, J., \& Vos, T. (2011). Cost-effectiveness of diet and exercise interventions to reduce overweight and obesity. International Journal of Obesity, 35(8), 1071-1078.

Gaston, A., \& Prapavessis, H. (2014). Using a combined protection motivation theory and health action process approach intervention to promote exercise during pregnancy. Journal of Behavioral Medicine, 37(2), 173-184.

Gebel, K., Ding, D., Chey, T., Stamatakis, E., Brown, W. J., \& Bauman, A. E. (2015). Effect of moderate to vigorous physical activity on all-cause mortality in middle-aged and older Australians. Journal of the American Medical Association of Internal Medicine, 175(6), 970-977.

Glass, T. A., \& McAtee, M. J. (2006). Behavioral science at the crossroads in public health: extending horizons, envisioning the future. Social Science \& Medicine, 62(7), 1650-1671.

Greaves, C. J., Sheppard, K. E., Abraham, C., Hardeman, W., Roden, M., Evans, P. H., \& Schwarz, P. (2011). Systematic review of reviews of intervention components associated with increased effectiveness in dietary and physical activity interventions. Behavioural Medicine Journal for Public Health, 11(1), 1.

Hanson, M. D., \& Chen, E. (2007). Socioeconomic status and health behaviors in adolescence: a review of the literature. Journal of Behavioral Medicine, 30(3), 263-285.

Hattar, A., Pal, S., \& Hagger, M. S. (2016). Predicting physical activity-related outcomes in overweight and obese adults: A health action process approach. Applied Psychology: Health and Well-Being, 8(1), $127-151$.

Headspace National Youth Mental Health Foundation. (2017). Majority of Aussie students stressed, depressed. Retrieved August 6, 2017, from https://www.headspace.org.au/news/majority-of-aussie-studentsstressed-depressed/ 
Hutchinson, A. D., \& Wilson, C. (2012). Improving nutrition and physical activity in the workplace: a metaanalysis of intervention studies. Health Promotion International, 27(2), 238-249.

Hutchison, A. J., Breckon, J. D., \& Johnston, L. H. (2009). Physical activity behavior change interventions based on the transtheoretical model: A systematic review. Health Education \& Behavior, 36(5), 829845 .

Ingledew, D. K., \& McDonagh, G. (1998). What coping functions are served when health behaviours are used as coping strategies? Journal of Health Psychology, 3(2), 195-213.

Josefsson, T., Lindwall, M., \& Archer, T. (2014). Physical exercise intervention in depressive disorders: Metaanalysis and systematic review. Scandinavian Journal of Medicine \& Science in Sports, 24(2), 259272.

Kanfer, F. H. (1971). The maintenance of behavior by self-generated stimuli and reinforcement. The Psychology of Private Events, 39-59.

Kanfer, F. H., \& Goldstein, A. P. (1975). Helping people change: A textbook of methods. Pergamon Press.

Karoly, P. (2012). Self-Regulation. In W. O'Donohue, J. E. Fisher (Eds.), Cognitive Behavior Therapy: Core Principles for Practice (pp. 183-213). John Wiley and Sons. doi: 10.1002/9781118470886.ch8

Kinmonth, A. L., Wareham, N. J., Hardeman, W., Sutton, S., Prevost, A. T., Fanshawe, T., ... \& Griffin, S. J. (2008). Efficacy of a theory-based behavioural intervention to increase physical activity in an at-risk group in primary care (ProActive UK): A randomised trial. The Lancet, 371(9606), 41-48.

Keating, X. D., Guan, J., Piñero, J. C., \& Bridges, D. M. (2005). A meta-analysis of college students' physical activity behaviors. Journal of American College Health, 54(2), 116-126.

Kwan, M. Y., Cairney, J., Faulkner, G. E., \& Pullenayegum, E. E. (2012). Physical activity and other health-risk behaviors during the transition into early adulthood: a longitudinal cohort study. American Journal of Preventive Medicine, 42(1), 14-20.

Leslie, E., Owen, N., Salmon, J., Bauman, A., Sallis, J. F., \& Lo, S. K. (1999). Insufficiently active Australian college students: Perceived personal, social, and environmental influences. Preventive Medicine, 28(1), 20-27.

Mastellos, N., Gunn, L. H., Felix, L. M., Car, J., \& Majeed, A. (2014). Transtheoretical model stages of change for dietary and physical exercise modification in weight loss management for overweight and obese adults. The Cochrane Library.

McKee, H. C., \& Ntoumanis, N. (2014). Developing self-regulation for dietary temptations: Intervention effects on physical, self-regulatory and psychological outcomes. Journal of Behavioral Medicine, 37(6), 10751081 .

Michie, S., Abraham, C., Whittington, C., McAteer, J., \& Gupta, S. (2009). Effective techniques in healthy eating and physical activity interventions: a meta-regression. Health Psychology, 28(6), 690.

Michie, S., Ashford, S., Sniehotta, F. F., Dombrowski, S. U., Bishop, A., \& French, D. P. (2011). A refined taxonomy of behaviour change techniques to help people change their physical activity and healthy eating behaviours: the CALO-RE taxonomy. Psychology \& Health, 26(11), 1479-1498.

Michie, S., \& Johnston, M. (2012). Theories and techniques of behaviour change: Developing a cumulative science of behaviour change. Health Psychology Review, 6(1), 1-6.

Miller, W. R., \& Rollnick, S. (2012). Motivational interviewing: Helping people change. New York, NY: Guilford Press.

Moyers, T. B., Martin, T., Manuel, J. K., Hendrickson, S. M., \& Miller, W. R. (2005). Assessing competence in the use of motivational interviewing. Journal of Substance Abuse Treatment, 28(1), 19-26.

Noar, S. M., \& Zimmerman, R. S. (2005). Health Behavior Theory and cumulative knowledge regarding health behaviors: Are we moving in the right direction? Health Education Research, 20(3), 275-290.

O’Halloran, P. D., Blackstock, F., Shields, N., Holland, A., Iles, R., Kingsley, M., ... \& Taylor, N. F. (2014). Motivational interviewing to increase physical activity in people with chronic health conditions: a systematic review and meta-analysis. Clinical Rehabilitation, 28(12), 1159-1171. Doi: $10.1177 / 0269215514536210$. 
Pignataro, R. M., James Huddleston, P. (2015). The use of motivational interviewing in physical therapy education and practice: Empowering patients through effective self-management. Journal of Physical Therapy Education, 29(2), 62.

Prochaska, J. O., \& DiClemente, C. C. (1982). Transtheoretical therapy: Toward a more integrative model of change. Psychotherapy: Theory, Research \& Practice, 19(3), 276.

Prochaska, J. O., \& Velicer, W. F. (1997). The transtheoretical model of health behavior change. American Journal of Health Promotion, 12(1), 38-48.

Raedeke, T. D., Focht, B. C., \& King, J. S. (2010). The impact of a student-led pedometer intervention incorporating cognitive-behavioral strategies on step count and self-efficacy. Research Quarterly for Exercise and Sport, 81(1), 87-96.

Rhee, C. W., Kim, J. Y., Park, B. J., Li, Z. M., \& Ahn, Y.-O. (2012). Impact of individual and combined health behaviors on all causes of premature mortality among middle aged men in Korea: The Seoul male cohort Study. Journal of Preventive Medicine and Public Health, 45(1), 14-20.

Rogers, R. W. (1975). A protection motivation theory of fear appeals and attitude change 1. Journal of Psychology, 91(1), 93-114.

Rogers, R. W. (1983). Cognitive and psychological processes in fear appeals and attitude change: A revised theory of protection motivation. In J.T. Cacioppo (Ed.), Social psychophysiology: A sourcebook (pp 153-176). Guilford Press: Guildford.

Rosenstock, I. M. (1966). Why people use health services. Milbank Memorial Fund Quarterly, 83(4), 94-124.

Rosenstock, I. M. (1974). Historical origins of the health belief model. Health Education Monographs, 2(4), 328-335.

Rosenstock, I. M., Strecher, V. J., \& Becker, M. H. (1988). Social learning theory and the health belief model. Health Education \& Behavior, 15(2), 175-183.

Rouse, P., \& Biddle, S. (2010). An ecological momentary assessment of the physical activity and sedentary behaviour patterns of university students. The Health Education Journal, 69(1), 116-116.

Roux, A. V. D. (2004). The study of group-level factors in epidemiology: rethinking variables, study designs, and analytical approaches. Epidemiologic Reviews, 26(1), 104-111.

Schuch, F. B., Vancampfort, D., Richards, J., Rosenbaum, S., Ward, P. B., \& Stubbs, B. (2016). Exercise as a treatment for depression: A meta-analysis adjusting for publication bias. Journal of Psychiatric Research, 77, 42-51.

Schwarzer, R., \& Luszczynska, A. (2008). How to overcome health-compromising behaviors: The health action process approach. European Psychologist, 13(2), 141-151.

Shiroma, E. J., \& Lee, I.-M. (2010). Physical activity and cardiovascular health lessons learned from epidemiological studies across age, gender, and race/ethnicity. Circulation, 122(7), 743-752.

Sigmundová, D., Chmelik, F., Sigmund, E., Feltlová, D., \& Frömel, K. (2013). Physical activity in the lifestyle of Czech university students: Meeting health recommendations. European Journal of Sport Science, 13(6), 744-750.

Sniehotta, F. F., Scholz, U., \& Schwarzer, R. (2005). Bridging the intention-behaviour gap: Planning, selfefficacy, and action control in the adoption and maintenance of physical exercise. Psychology \& Health, 20(2), 143-160.

Sniehotta, F. F., Scholz, U., \& Schwarzer, R. (2006). Action plans and coping plans for physical exercise: A longitudinal intervention study in cardiac rehabilitation. British Journal of Health Psychology, 11(1), 23-37.

Stallman, H. (2010). Psychological distress in university students: A comparison with general population data. Australian Psychologist, 45(4), 249-257. doi:10.1080/00050067.2010.482109

Stenholm, S., Head, J., Kivimäki, M., Kawachi, I., Aalto, V., Zins, M., ... \& Vahtera, J. (2016). Smoking, physical inactivity and obesity as predictors of healthy and disease-free life expectancy between ages 50 and 75: A multicohort study. International Journal of Epidemiology, 45(4), 1260-1270.

Storrie, K., Ahern, K., \& Tuckett, A. (2010). A systematic review: students with mental health problems-a growing problem. International Journal of Nursing Practice, 16(1), 1-6. 
Van Stralen, M., De Vries, H., Mudde, A., Bolman, C., \& Lechner, L. (2009). Determinants of initiation and maintenance of physical activity among older adults: A literature review. Health Psychology Review, 3(2), 147-207. doi:10.1080/17437190903229462

Stubbs, B., Vancampfort, D., Rosenbaum, S., Ward, P. B., Richards, J., Soundy, A., Veronese, N., et al. (2016). Dropout from exercise randomized controlled trials among people with depression: A meta-analysis and meta regression. Journal of Affective Disorders, 190, 457-466.

Sussman, S., Sun, P., \& Dent, C. W. (2006). A meta-analysis of teen cigarette smoking cessation. Health Psychology, 25(5), 549.

Vella-Zarb, R., \& Elgar, F. (2009). The 'Freshman 5': A meta-analysis of weight gain in the freshman year of college. Journal of American College Health, 58(2), 161-166.

Voss, M. W., Nagamatsu, L. S., Liu-Ambrose, T., \& Kramer, A. F. (2011). Exercise, brain, and cognition across the life span. Journal of Applied Physiology, 111(5), 1505-1513.

Webb, T. L., Sniehotta, F. F., \& Michie, S. (2010). Using theories of behaviour change to inform interventions for addictive behaviours. Addiction, 105(11), 1879-1892.

Weinstein, N. D., \& Rothman, A. J. (2005). Commentary: Revitalizing research on health behavior theories. Health Education Research, 20(3), 294-297.

Williams, S., \& French, D. (2011). What are the most effective intervention techniques for changing physical activity self-efficacy and physical activity behaviour-and are they the same? Health Education Research, 26(2), 308-322.

Winzer, B. M., Whiteman, D. C., Reeves, M. M., \& Paratz, J. D. (2011). Physical activity and cancer prevention: a systematic review of clinical trials. Cancer Causes \& Control, 22(6), 811-826

The author may be contacted via

stef.black@gmail.com 